\title{
POLYMORPHISM OF THE $A D R B 2$ rs1042713 GENE IS NOT ASSOCIATED WITH SPONTANEOUS PRETERM BIRTH: ANALYSES IN A SLOVENIAN SAMPLE AND META ANALYSIS
}

\author{
Peterlin $\mathrm{A}^{1}$, Maver $\mathrm{A}^{1}$, Jan $\mathrm{Z}^{2}$, Lovrecic $\mathrm{L}^{1}$, Tul $\mathrm{N}^{2}$, Peterlin $\mathrm{B}^{1}$
}

*Corresponding Author: Professor Borut Peterlin, Clinical Institute of Medical Genetics, Division of Obstetrics and Gynecology, University Medical Centre Ljubljana, Šlajmerjeva 3, 1000 Ljubljana, Slovenia. Tel/Fax: +386-1-5401-137. E -mail: borut.peterlin@guest.arnes.si

\section{ABSTRACT}

The $\beta$-2-adrenergic receptor (ADRB2) gene has an important impact on smooth muscle relaxation, including the smooth muscles of the uterus. The results of previously published studies of the association between the ADRB2 rs 1042713 polymorphism and spontaneous preterm birth (SPTB) were inconsistent. We evaluated the association between $A D R B 2$ and SPTB in a case-control association study in a Slovenian sample population and performed a meta analysis of previously published studies. No association was found between the polymorphism in the ADRB2 gene and SPTB in the Slovenian sample of 98 SPTB patients and 135 controls under dominant $\left[\chi^{2}=\right.$ $0.01, p=0.92$, odds ratio $(\mathrm{OR})=1.03,95 \%$ confidence interval $(95 \% \mathrm{CI})=0.52-2.04)$, recessive $\left(\chi^{2}=0.01, p=\right.$ $0.92, \mathrm{OR}=0.98,95 \% \mathrm{CI}=0.57-1.70)$ and codominant genetic models $\left(\chi^{2}=0.01, p=0.92, \mathrm{OR}=0.99,95 \% \mathrm{CI}\right.$ $=0.59-1.68)$. The meta analysis of a pooled sample of 404 SPTB patients and 878 controls suggested no association of $A D R B 2$ polymorphism and SPTB under dominant (OR $=1.12,95 \% \mathrm{CI}=0.81-1.54)$ and recessive genetic models $(\mathrm{OR}=0.84,95 \% \mathrm{CI}=0.64-1.12)$. These findings suggest no association between the ADRB2 rs1042713 gene polymorphism and SPTB. Further association studies with larger sample sizes are needed.

Keywords: $\beta$-2-Adrenergic receptor (ADRB2) gene; Case-control association study; Meta analysis; Risk factor; Spontaneous preterm birth (SPTB).

\footnotetext{
${ }^{1}$ Clinical Institute of Medical Genetics, University Medical Centre Ljubljana, Ljubljana, Slovenia

${ }^{2}$ Department of Perinatology, Division of Obstetrics and Gynecology, University Medical Centre Ljubljana, Ljubljana, Slovenia
}

\section{INTRODUCTION}

Spontaneous preterm birth (SPTB) is the leading cause of neonatal morbidity and mortality worldwide. Approximately $12.0 \%$ of all infants are born preterm in the USA; this figure is $6.0-12.0 \%$ in the European Union (EU) $[1,2]$, and $7.6 \%$ in Slovenia [3].

Infants born preterm can suffer from lifelong morbidities such as developmental delay, lung disease, vision, and hearing deficits, as well as other neurosensory impairments $[4,5]$. They are also predisposed to hypertension and diabetes in adult life [6].

The etiology of SPTB is multifactorial. In addition to multiple gestations and assisted reproductive technologies, several environmental contributors to SPTB have been proposed, such as an infection [7,8], maternal smoking during pregnancy $[9,10]$, maternal/fetal stress [11,12], adolescence or advanced maternal age [13], cervical dysfunction [14], decidual thrombosis [15], and metabolic enzyme variation [14]. In about $70.0 \%$ of SPTB cases no risk factor can be identified, which makes genetic contribution a likely cause to be considered [16]. The role of genetic predisposition to SPTB is based on epidemiological evidence showing that SPTB tends to recur in families. Mothers with previous preterm deliveries have a significantly increased risk of preterm delivery in subsequent pregnancies [17-20]. Spontaneous preterm birth also occurs across generations and sibships [18,21-23]. The heri-tability of SPTB has been estimated to be in the range of 27.0-36.0\% [24,25].

Based on their potential role in pathogenesis, as many as 482 genes have already been tested for genetic association with SPTB (HuGENavigator), however, validation of study results remains challenging [26,27]. One of the most frequently investigated candidate genes is the $\beta-2-$ adrenergic receptor (ADRB2) gene. 
$\beta$-2-Adrenergic receptors, members of the superfamily of $\mathrm{G}$ protein-coupled receptors, mediate the catecholamineinduced activation of the adenylate cyclase signaling cascade, a mechanism that plays an important role in smooth muscle relaxation [28]. They are ubiquitously expressed in numerous human tissues, including smooth muscle cells of the trachea, bronchi, vasculature and the uterus. Uterine contractility is modulated by stimulation of $A D R B 2 \mathrm{~s}$ with endogenous and exogenous agonists that have a potential to affect cervical tone and resistance to mechanical stretching [29]. Therefore, we hypothesized that genetic variability in the $A D R B 2$ gene modulates uterine contractility and might be consequently associated with SPTB.

Several association studies have linked $A D R B 2$ polymorphism rs 1042713 and SPTB, but the results were found to be inconsistent [30-33]. Selected polymorphism is a missense polymorphism that results in amino acid change $\mathrm{R}(\mathrm{Arg}) \rightarrow \mathrm{G}$ (Gly). To address the role of $A D R B 2$ in SPTB, we conducted a two-stage study. First, we designed a casecontrol study, where we investigated whether maternal single nucleotide polymorphism of ADRB2 rs1042713 is associated with the risk of SPTB in the Slovenian population. Second, we carried out a meta analysis to systematically review the association of $A D R B 2$ rs1042713 with SPTB, including the results of this and previously published case-control studies.

\section{MATERIALS AND METHODS}

Case-Control Association Study in the Slovenian Population. Participants of the study all signed a written informed consent. The Republic of Slovenia National Medical Ethics Committee approved the study.

Definition of SPTB and Inclusion Criteria for the SPTB Cases. We included healthy mothers with singleton pregnancies who delivered after a spontaneous onset of labor (SPTB) before completed 37 weeks' gestation. Ges- tational age was determined by the last menstrual period and confirmed by an ultrasound examination in the first trimester. Cases with known risk factors for SPTB (e.g., diabetes, hypertension, kidney disease, autoimmune conditions, infections, uterine malformations and complications during pregnancy) or neonates born with congenital anomalies or evidence of infection were excluded. All analyzed subjects were of Caucasian origin. Additional information on maternal characteristics is shown in Table 1.

Study Sample in the Case-Control Association Analyses. We conducted a case-control study including 98 female patients with SPTB and 135 female controls who gave birth at the Division of Obstetrics and Gynecology, University Medical Centre in Ljubljana, Slovenia. Controls were age-matched healthy mothers who delivered after an uncomplicated pregnancy after 37 weeks and delivered a neonate with appropriate-for-gestational-age birth weight (Table 1).

Genotype Analyses. Genomic DNA was isolated from peripheral blood leukocytes using standard procedures. Real-time polymerase chain reaction (PCR) method performed on a 7000 Sequence Detection System (Applied Biosystems, Foster City, CA, USA) using KASPar SNP genotyping chemistry carried out genotyping of the single nucleotide polymorphism (SNP). The PCR reaction mix of $8 \mu \mathrm{L}$ final volume consisted of $3 \mu \mathrm{L}$ of DNA sample, $4 \mu \mathrm{L}$ of reaction mix $2 \mathrm{X}, 0.11 \mu \mathrm{L}$ assay mix and $0.89 \mu \mathrm{L} \mathrm{H}_{2} \mathrm{O}$. The protocol for PCR amplification was as follows: initial denaturation step at $94{ }^{\circ} \mathrm{C}$ for $15 \mathrm{~min}$., then 10 cycles of denaturation at $94^{\circ} \mathrm{C}$ for 20 seconds, followed by $5 \mathrm{sec}$ onds at $57^{\circ} \mathrm{C}$ or $61^{\circ} \mathrm{C}, 10$ seconds at $72^{\circ} \mathrm{C}, 10$ seconds at $94{ }^{\circ} \mathrm{C}, 20$ seconds at $57^{\circ} \mathrm{C}$ or $61^{\circ} \mathrm{C}$, and final extension at $72{ }^{\circ} \mathrm{C}$ for 40 seconds. The allelic discrimination analysis was performed using SDS Software Version 1.2 (Applied Biosystems). Genotype assignment was performed and interpreted independently by two investigators.

Statistical Analyses. We analyzed the significance of associations between allelic and genotype frequencies

Table 1. Characteristics of 98 mothers with SPTB and 135 controls.

\begin{tabular}{|c|c|c|c|}
\hline Parameters & SPTB & Controls & $p$ Value \\
\hline Mean maternal age (years) & $30.20 \pm 4.59$ & $30.10 \pm 3.92$ & 0.28 \\
\hline Smoking during pregnancy $\%(n)$ & $8.3(8)$ & $2.9(4)$ & 0.15 \\
\hline Previous SPTB \% $(n)$ & $12.4(12)$ & $4.3(6)$ & 0.08 \\
\hline In vitro fertilization $\%(n)$ & $4.1(4)$ & $1.4(2)$ & 0.31 \\
\hline Urogenital infections $\%(n)$ & $7.2(7)$ & $4.3(6)$ & 0.35 \\
\hline High blood pressure $\%(n)$ & $7.2(7)$ & $4.3(6)$ & 0.35 \\
\hline Stressful events during pregnancy $\%(n)$ & $3.1(3)$ & $4.3(6)$ & 0.50 \\
\hline
\end{tabular}

SPTB: spontaneous preterm birth. 
and disease status using the $\chi^{2}$ test. Odds ratios (ORs) and their respective $95 \%$ confidence intervals ( $95 \%$ CIs), were calculated to compare allelic and genotype distribution in patients and controls. To provide an additional quality step of the genotyping process we calculated the $\chi^{2}$ goodnessof-fit tests for deviation of genotype distribution from those predicted by Hardy-Weinberg equilibrium. The investigated associations were regarded as significant when they reached $p \leq 0.05$. The $\mathrm{R}$ statistical language (version 3.0) was used to perform the analyses.

To calculate the power of the study DSS Researcher's Toolkit (https://www.dssresearch.com/Knowledge Center/ toolkitcalculators/statisticalpowercalculators.aspx) was utilized. Calculations showed that our power to detect a significant result in the presence of the actual genotype relative risk equal to at least 2.0 was $85.8 \%$ when taking into account the sample size, the significance threshold of 0.05 , and the risk genotype frequency of $15 \%$.

Meta Analyses. A literature search to find potential eligible studies of the association between ADRB2 rs 1042713 and SPTB was conducted in PubMed (National Center for Biotechnology Information, January 1966-December 2016), Scopus (December 2016), Google Scholar (December 2016), and HugeNavigator (December 2016). We limited our search to articles in the English language. Keywords searched included: (ADRB2 or $\beta$-2-adrenergic receptor gene or polymorphisms) AND (preterm birth or preterm labor). The AND operator was used to create various combinations of selected terms. Studies were selected and reviewed by two independent authors who reached a consensus on all of the items.

Study Selection and Data Extraction. We included human studies meeting following criteria: 1) a genotype of $A D R B 2$ rs 1042713 and 2) case-control study in which genotyping was carried out for the group of SPTB cases and control group; 3), SPTB defined as $<37$ weeks' gestation; 4) control group defined as women who gave birth after 37 weeks' gestation. For each study included in the meta analysis, we extracted authors, year of publication, study population geographic origins, number of SPTB cases and controls, SPTB definition, an occurrence of preterm premature rupture of membranes (PPROM), inclusion criteria for control women, and genotype count for SPTB cases and controls.

We classified subjects into three genotypes: AA, GA and GG. Then pooled effect was calculated for the dominant genetic model (GA+GG vs. AA) and recessive genetic model (AA+GA vs. GG) in the ADRB2 rs1042713 polymorphism. Cochrane's $\mathrm{Q}$ and $\mathrm{I}^{2}$ tests were used to assess heterogeneity between the studies, with the null

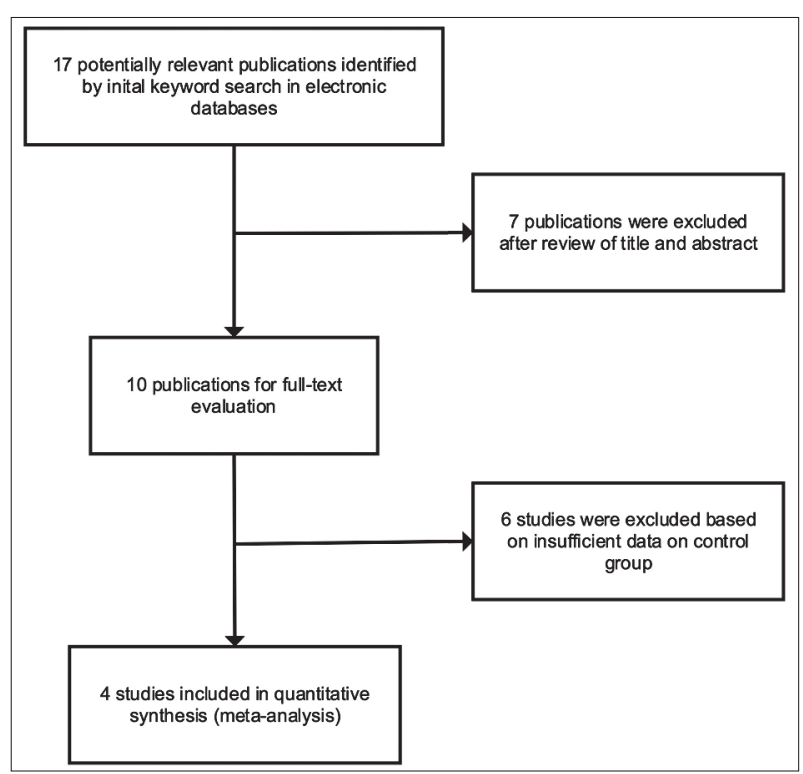

Figure 1. Flowchart of study selection process in the meta analysis.

hypothesis that there is no difference in findings of primary studies. Heterogeneity was considered significant when $p<0.1$ for Cochrane's Q statistics. Random effect model (der Simonian-Laird) was applied upon the detection of heterogeneity; otherwise, fixed effect model (MaentelHaenszel) was used. The random effect model takes into account diversity of included studies due to intra-study sampling errors and inter-study variances, while the fixed effect model assumes that the observed variations between studies are caused by chance alone. Publication bias was assessed by Funnel plot. The asymmetry of the Funnel plot was analyzed with the Egger's test. The analysis was carried out with the $\mathrm{R}$ statistical language (version 3.0).

\section{RESULTS}

Case-Control Association Study in the Slovenian

Population. Cases and controls did not differ in any demographic characteristic or recognized risk factor for SPTB. The history of a previous SPTB was more frequent in the SPTB group (12.4\%) in comparison to controls (4.3\%), however, the difference did not reach statistical significance (Table 1).

Genotype frequencies of investigated polymorphisms were in accordance with those predicted by the HardyWeinberg equilibrium in the group of patients and in the control group. Genotype and allelic distribution of the $A D R B 2$ polymorphism of the 98 SPTB patients and 135 controls are shown in Table 2. The ADRB2 rs1042713 
genotypes were not found to be associated with the risk of SPTB in the Slovene population under any of the investigated models, dominant, recessive, and codominant (Table 3).

Meta Analyses. The initial keyword search identified 17 articles (Figure 1). Four previously published casecontrol studies were included after a review together with added results of our case-control study based on characteristics summarized in Table 4. Therefore, five studies met inclusion criteria with a total of 404 SPTB cases and 878 term controls.
Association of Genotype and Phenotype. Cochrane's Q test and $\mathrm{I}^{2}$ test showed that there was no evidence of heterogeneity across all studies under the recessive genetic model, while moderate heterogeneity was present under the dominant genetic model. We found that there was no significant association of ADRB2 rs 1042713 polymorphism with SPTB under the dominant (AA+GA vs. $\mathrm{GG})$ or recessive $(\mathrm{GG} v s$. $\mathrm{AA}+\mathrm{GA})$ genetic models (Figure 2). We analyzed the asymmetry of the funnel plot with Egger's test and found no evidence for publication bias.

Table 2. Genotype and allelic distribution of the $A D R B 2$ rs1042713 polymorphism of the 98 SPTB patients and 135 controls.

\begin{tabular}{|l|c|c|c|c|c|c|c|c|c|}
\hline Parameters & \multicolumn{4}{|c|}{ Genotype Frequencies $\boldsymbol{n}(\%)$} & \multicolumn{4}{c|}{ Allele Frequencies $(\boldsymbol{n})$ \% } \\
\hline & AA & GA & GG & $p$ Value & $\chi^{2}$ & A & G & $p$ Value & $\chi^{2}$ \\
\hline SPTB cases & $17(17.3)$ & $48(49.0)$ & $33(33.7)$ & 0.99 & 0.01 & $65(42.0)$ & $81(42.0)$ & 1.0 & 0 \\
\hline Controls & $24(18.0)$ & $66(49.0)$ & $45(33.0)$ & & & $90(58.0)$ & $111(58.0)$ & & \\
\hline
\end{tabular}

SPTB: spontaneous preterm birth.

Table 3. Association of $A D R B 2$ rs 1042713 with SPTB under different genetic models.

\begin{tabular}{|l|c|c|c|c|}
\hline \multicolumn{1}{|c|}{ Genetic Model } & & \multicolumn{3}{c|}{ W $_{\text {SPTB }}$ vs. $\mathbf{W}_{\mathrm{C}}$} \\
\hline & & OR $(95 \%$ CI $)$ & $p$ Value & $\chi^{2}$ \\
\hline Dominant & GA+GG vs. AA & $1.03(0.52-2.04)$ & 0.92 & 0.01 \\
\hline Recessive & AA+GA vs. GG & $0.98(0.57-1.70)$ & 0.92 & 0.01 \\
\hline Codominant & AA+GG vs. GA & $0.99(0.59-1.68)$ & 0.92 & 0.01 \\
\hline
\end{tabular}

SPTB: spontaneous preterm birth; OR: odds ratio; $95 \% \mathrm{CI}$ : confidence interval; $\mathrm{W}_{\mathrm{SРTB}}$ : $\mathrm{SPTB}$ women; $\mathrm{W}_{\mathrm{C}}$ : control women.

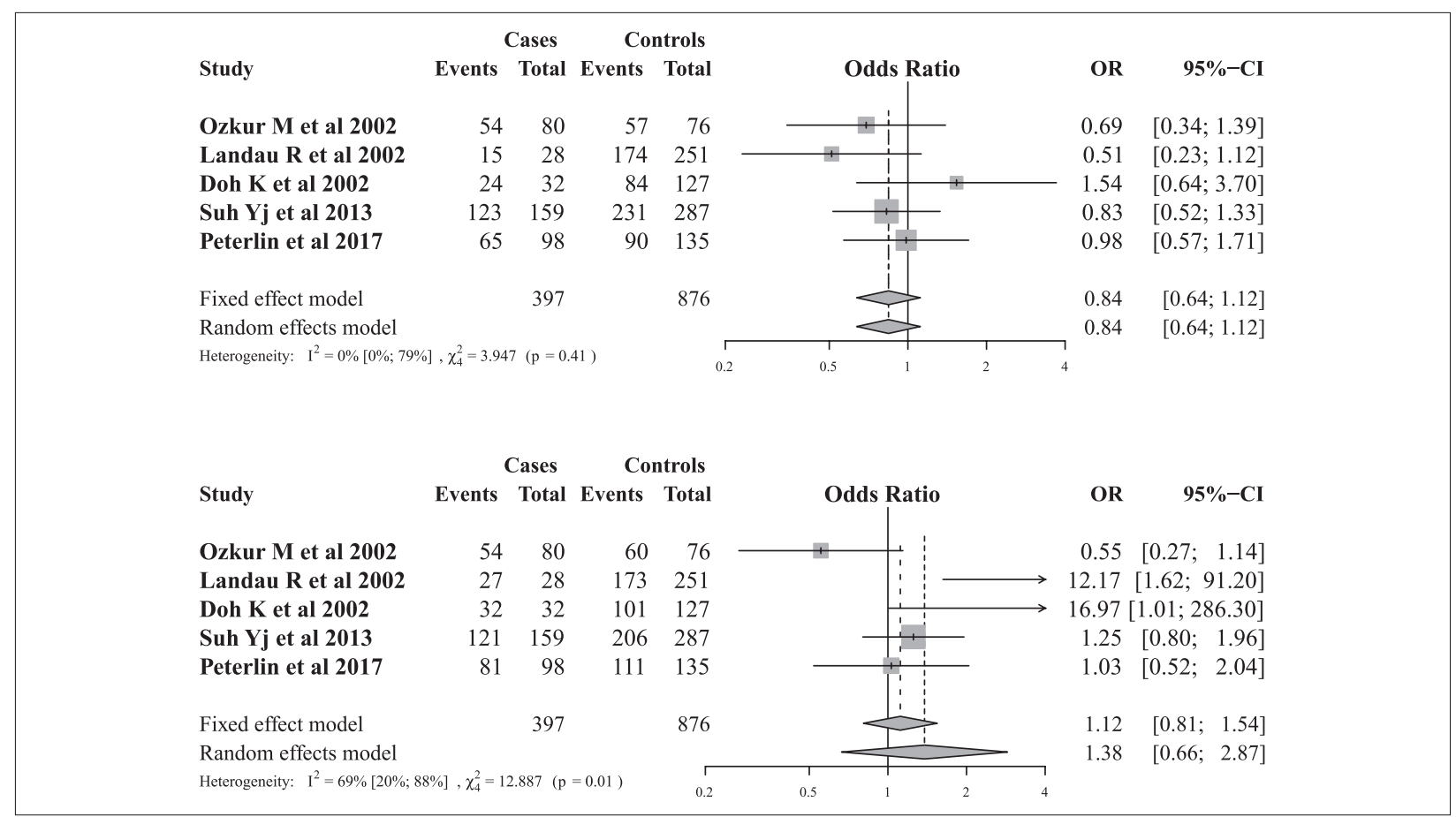

Figure 2. Forest plots for the association between the $A D R B 2$ rs 1042713 polymorphism and SPTB risk in recessive and dominant genetic models. 
Table 4. Characteristics of studies included in the meta analysis.

\begin{tabular}{|l|c|l|l|c|c|c|c|c|}
\hline \multicolumn{1}{|c|}{ Refs. } & Year & Country & Population & $\begin{array}{c}\text { PPROM } \\
\text { Excluded }\end{array}$ & $\begin{array}{c}\text { SPTB Cases } \\
\text { Criteria }\end{array}$ & $\begin{array}{c}\text { Case } \\
\text { Sample Size }\end{array}$ & $\begin{array}{c}\text { Control } \\
\text { Criteria }\end{array}$ & $\begin{array}{c}\text { Control } \\
\text { Group Size }\end{array}$ \\
\hline this study & 2017 & Slovenia & Caucasian & no & GA $<37$ & 98 & GA $>37$ & 135 \\
\hline$[30]$ & 2013 & Korea & Asian & no & GA $<37$ & 166 & GA $>37$ & 289 \\
\hline$[31]$ & 2004 & Hungary & Caucasian & no & GA $<37$ & 32 & GA $>37$ & 127 \\
\hline$[33]$ & 2002 & Turkey & Caucasian & yes & GA $<37$ & 80 & GA $>37$ & 76 \\
\hline$[32]$ & 2002 & USA & Hispanic & no & GA $<37$ & 28 & GA $>37$ & 251 \\
\hline
\end{tabular}

PPROM: preterm premature rupture of the membranes; SPTB: spontaneous preterm birth; GA: gestational age.

\section{DISCUSSION}

In the case-control association study in the Slovenian population and meta-analysis of previous studies, we did not find any evidence of an association between SPTB and $A D R B 2$ rs1042713. In the Slovenian population case-control association study, we also did not find any difference in ADRB2 rs 1042713 polymorphism allele and genotype distribution between SPTB and controls. The arginine (A allele) at rs 1042713 was reported to be associated with reduced downregulation of gene expression and reduced desensitization of ADRB2 leading to a change in the responsiveness to circulating endogenous $\beta$-agonists shown in Figure $3[34,35]$. Thus, it was suggested that down-regulation of $A D B R 2$ could play a role in the timing of labor, especially as ADRB2 agonists in some cases appear to prevent preterm delivery $[36,37]$.

This led us, and other authors, to investigate the association between the $A D R B 2$ rs 1042713 polymorphism and SPTB. While case-control association studies conducted in the Hungarian and Hispanic populations proposed that homozygosity for ADRB2 rs1042713 (AA genotype) protects against SPTB $[31,32]$, our study and studies in the

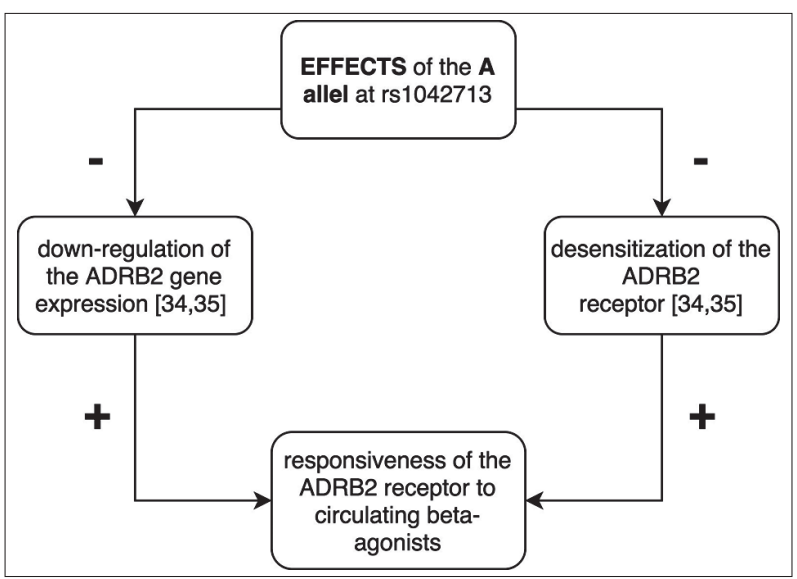

Figure 3. Effects of the $A D R B 2$ rs 1042713 A allele on the ADRB2 receptor.
Korean and Turkish populations have not found any evidence of genotype AA effect on SPTB [30,33]. Both studies reporting an association between ADRB2 rs1042713 polymorphism and preterm birth (PTB) had small sample sizes, especially in the group of patients suffering from PTB, which leads to a lower statistical power to detect small effects of the studied polymorphism. The results of the studies could also be influenced by ethnical diversity among the participants.

The results of genetic association studies quite frequently fail to be reproduced in subsequent studies, either because the original findings are false-positive reports, or because the small genetic effects were not detectable [38]. Large sample sizes or meta-analysis are required in order to identify the small genetic effects of polymorphisms [39]. A meta analysis is a statistical tool that enables objective, quantitative synthesis of research findings, thus overcoming the problem of a small sample size and the inadequate statistical strength of genetic association studies [40].

To further investigate the role of the $A D R B 2$ rs1042713 polymorphism and SPTB we performed a meta analysis of four previously published case-control association studies and our study [30,33]. The evidence for association was found neither under the recessive nor dominant genetic models.

Alternatively, the previously published meta analysis of three reports, including both studies that found association [31,32] and studies by Ozkur et al. [33] and Dolan et al. [41], suggested a nominally significant association. Our study has some limitations. On the one hand, the study in the Slovenian population had limited power to detect small effects of the studied polymorphism. On the other hand, the size of studies included in the meta analysis was small and of heterogeneous genetic background. Additionally, we found evidence of moderate heterogeneity under the dominant genetic model in our meta analysis. We only included studies in the English language; therefore, we might have missed potential association studies linking $A D R B 2$ rs 1042713 to SPTB. 
In conclusion, both the association study in the Slovenian population and meta analysis showed no evidence of an association between ADRB2 rs1042713 and SPTB. Further larger association studies on the topic are needed to reach a more definite conclusion.

Declaration of Interest. The authors report no conflicts of interest. The authors alone are responsible for the content and writing of this article.

Funding. This study was supported by a grant P30326 from the Slovenian Research Agency (to B. Peterlin).

\section{REFERENCES}

1. Beck S, Wojdyla D, Say L, Betran AP, Merialdi M, Requejo JH, et al. The worldwide incidence of preterm birth: A systematic review of maternal mortality and morbidity. Bull World Health Organ. 2010; 88(1): 31-38.

2. Blencowe H, Cousens S, Oestergaard MZ, Chou D, Moller AB, Narwal R, et al. National, regional, and worldwide estimates of preterm birth rates in the year 2010 with time trends since 1990 for selected countries: A systematic analysis and implications. Lancet. 2012; 379(9832): 2162-2172.

3. Macfarlane A, Dattani N, Mohangoo A, Zeitlin J. What can the UK learn from international comparisons of routinely collected perinatal data? UK perspectives on the Euro-Peristat project. Lancet. 2013; 382:S67.

4. Huddy CL, Johnson A, Hope PL. Educational and behavioural problems in babies of 32-35 weeks gestation. Arch Dis Child Fetal Neonatal Ed. 2001; 85(1): F23-F28.

5. Fawke J. Neurological outcomes following preterm birth. Semin Fetal Neonatal Med. 2007; 12(5): 374-382.

6. Eriksson JG. The fetal origins hypothesis -10 years on. BMJ. 2005; 330(7500): 1096-1097.

7. Hay PE, Lamont RF, Taylor-Robinson D, Morgan DJ, Ison C, Pearson J. Abnormal bacterial colonisation of the genital tract and subsequent preterm delivery and late miscarriage. BMJ. 1994; 308(6924): 295-298.

8. Meis P. The preterm prediction study: Significance of vaginal infections *1, *2. Am J Obstet Gynecol. 1995; 173(4): 1231-1235.

9. Nabet C, Ancel PY, Burguet A, Kaminski M. Smoking during pregnancy and preterm birth according to obstetric history: French national perinatal surveys. Paediatr Perinat Epidemiol. 2005; 19(2): 88-96.

10. Khader YS, Al-Akour N, AlZubi IM, Lataifeh I. The association between second hand smoke and low birth weight and preterm delivery. Matern Child Health J. 2011; 15(4): 453-459.

11. Copper RL, Goldenberg RL, Das A, Elder N, Swain M, Norman G, et al. The preterm prediction study: Maternal stress is associated with spontaneous preterm birth at less than thirty-five weeks' gestation. Am J Obstet Gynecol. 1996; 175(5): 1286-1292.

12. Orr ST, Reiter JP, Blazer DG, James SA. Maternal prenatal pregnancy-related anxiety and spontaneous preterm birth in Baltimore, Maryland. Psychosom Med. 2007; 69(6): 566-570.

13. Cnattingius $\mathrm{S}$, Forman MR, Berendes HW, Isotalo L. Delayed childbearing and risk of adverse perinatal outcome. A population-based study. JAMA. 1992; 268(7): 886-890.

14. Lockwood CJ, Kuczynski E. Risk stratification and pathological mechanisms in preterm delivery. Paediatr Perinat Epidemiol. 2001; 15(Suppl 2): 78-89.

15. Lockwood CJ. Pregnancy-associated changes in the hemostatic system. Clin Obstet Gynecol. 2006; 49(4): 836-843.

16. Goldenberg RL, Culhane JF, Iams JD, Romero R. Epidemiology and causes of preterm birth. Lancet. 2008; 371(9606): 75-84.

17. Adams MM, Elam-Evans LD, Wilson HG, Gilbertz DA. Rates of and factors associated with recurrence of preterm delivery. JAMA. 1995; 283(12): 1591-1596.

18. Bhattacharya S, Raja EA, Mirazo ER, Campbell DM, Lee AJ, Norman JE, et al. Inherited predisposition to spontaneous preterm delivery. Obstet Gynecol. 2010; 115(6): 1125-1133.

19. Winkvist A, Mogren I, Högberg U. Familial patterns in birth characteristics: Impact on individual and population risks. Int J Epidemiol. 1998; 27(2): 248-254.

20. Ward K, Argyle V, Meade M, Nelson L. The heritability of preterm delivery. Obstet Gynecol. 2005; 106(6): 1235-1239.

21. Porter T, Fraser A, Hunter C, Ward R, Varner M. The risk of preterm birth across generations. Obstet Gynecol. 1997; 90(1): 63-67.

22. Svensson AC, Sandin S, Cnattingius S, Reilly M, Pawitan Y, Hultman CM, et al. Maternal effects for pre- 
term birth: A genetic epidemiologic study of 630,000 families. Am J Epidemiol. 2009;170(11):1365-72.

23. Wilcox AJ, Skjærven R, Lie RT. Familial patterns of preterm delivery: Maternal and fetal contributions. Am J Epidemiol. 2008; 167(4): 474-479.

24. Clausson B, Lichtenstein P, Cnattingius S. Genetic influence on birthweight and gestational length determined by studies in offspring of twins. BJOG. 2000; 107(3): 375-381.

25. Treloar SA, Macones GA, Mitchell LE, Martin NG. Genetic influences on premature parturition in an Australian twin sample. Twin Res. 2000; 3(2): 80-82.

26. Yu W, Gwinn M, Clyne M, Yesupriya A, Khoury MJ. A navigator for human genome epidemiology. Nat Genet. 2008; 40(2): 124-125.

27. Crider KS, Whitehead N, Buus RM. Genetic variation associated with preterm birth: a HuGE review. Genet Med. 2005; 7(9): 593-604.

28. Pierce KL, Premont RT, Lefkowitz RJ. Seven-transmembrane receptors. Nat Rev Mol Cell Biol. 2002; 3(9): 639-650.

29. Bülbring E, Tomita T. Catecholamine action on smooth muscle. Pharmacol Rev. 1987; 39(1): 49-96.

30. Suh YJ, Park HJ, Lee KA, Lee BE, Ha EH, Kim YJ. Associations between genetic polymorphisms of Beta2 adrenergic receptor and preterm delivery in Korean women. Am J Reprod Immunol. 2013; 69(1): 85-91.

31. Doh K, Sziller I, Vardhana S, Kovacs E, Papp Z, Witkin SS. Beta-2-adrenergic receptor gene polymorphisms and pregnancy outcome. J Perinat Med. 2004; 32(5): 413-417.

32. Landau R, Xie HG, Dishy V, Stein CM, Wood AJJ, Moore JH, et al. Beta2-adrenergic receptor genotype and preterm delivery. Am J Obstet Gynecol. 2002; 187(5): 1294-1298.
33. Ozkur M, Dogulu F, Ozkur A, Gokmen B, Inaloz SS, Aynacioglu AS. Association of the Gln27Glu polymorphism of the beta-2-adrenergic receptor with preterm labor. Int J Gynecol Obstet. 2002; 77(3): 209-215.

34. Green SA, Turki J, Innis M, Liggett SB. Amino-terminal polymorphisms of the human beta 2-adrenergic receptor impart distinct agonist-promoted regulatory properties. Biochemistry. 1994; 33(32): 9414-9419.

35. Liggett SB. Beta-2-Adrenergic receptor pharma-cogenetics. Am J Respir Crit Care Med. 2000; 161(3 Pt 2): S197-S201.

36. Chanrachakul B, Matharoo-Ball B, Turner A, Robinson G, Broughton-Pipkin F, Arulkumaran S, et al. Reduced expression of immunoreactive beta2adrenergic receptor protein in human myometrium with labor. J Clin Endocrinol Metab. 2003; 88(10): 4997-5001.

37. Iams JD. The role of tocolysis in the prevention of preterm birth. Birth. 1996; 23(1): 40-41.

38. Ioannidis JP. Genetic associations: False or true? Trends Mol Med. 2003; 9(4): 135-138.

39. Lohmueller K, Pearce C, Pike M, Lander E, Hirschhorn J. Meta-analysis of genetic association studies supports a contribution of common variants to susceptibility to common disease. Nat Genet. 2003;33(2): 177-182.

40. Gotzsche P. Why we need a broad perspective on meta-analysis. BMJ. 2000; 321(7261): 585-586.

41. Dolan SM, Hollegaard MV, Merialdi M, Betran AP, Allen T, Abelow C, et al. Synopsis of preterm birth genetic association studies: The preterm birth genetics knowledge base (PTBGene). Public Health Genomics. 2010; 13(7-8): 514-523. 